Article

\title{
Prediction of Performance of a Variable-Pitch Axial Fan with Forward-Skewed Blades
}

\author{
Xuemin Ye $\mathbb{D}$, Fuwei Fan, Ruixing Zhang and Chunxi Li * \\ Department of Power Engineering, North China Electric Power University, Baoding 071003, China; \\ yexuemin@ncepu.edu.cn (X.Y.); fanfuwei00@163.com (F.F.); zhangruixinghd@163.com (R.Z.) \\ * Correspondence: lichunxi@ncepu.edu.cn or leechunxi@163.com; Tel.: +86-312-752-2891
}

Received: 25 April 2019; Accepted: 17 June 2019; Published: 19 June 2019

\begin{abstract}
For a single-stage variable-pitch axial fan, the aerodynamic performance and through flow with and without blade skewing are examined numerically. Simulated results show that the total pressure rise and efficiency increase by $2.99 \%$ and $0.16 \%$, respectively, with the best forward-skewed angle of $\theta=3^{\circ}$ at the design conditions. At the blade pitch angles of $\beta=29^{\circ}$ and $35^{\circ}$, the total pressure rises and efficiency of the fan with $\theta=3.0^{\circ}$ under the highest efficiency point change by $-0.55 \%$, $-0.53 \%$ and $1.39 \%, 2.11 \%$, respectively. At design and off-design conditions, the forward-skewed blades mitigate tip leakage and delay the emergence of separation flow at the blade root, these benefits are higher at the higher blade pitch angle. The $\theta=3.0^{\circ}$ forward skew effectively raises the stage performance of the impeller and guide vanes.
\end{abstract}

Keywords: variable-pitch axial fan; forward-skewed blades; aerodynamic performance; through flow

\section{Introduction}

A variable-pitch axial flow fan has many advantages over a fixed-pitch fan, such as a high operating efficiency, large flowrate, and larger operating range. Well-designed fans are important. They can account for more than $25 \%$ of the total power consumption in large-scale power plants, and the aerodynamic noise it generates is high [1,2]. To meet the different requirements of practical applications, the regulation of the working point is adjusted by varying the pitch angle of the rotating blades. This method has obvious merits, including high operating efficiency and stability, broad operating range, and wide applicability, compared with a fixed-pitch fan. As a result, variable-pitch axial fans are widely used in power generation and mining as primary fans, induced draft fans, and forced draft fans [1-3]. Therefore, studies on the aerodynamic performance and noise of such fans have tangible practical significance for energy conservation and noise reduction.

The circumferentially skewed blades can effectively improve the aerodynamic and acoustic performance of axial fans. Li et al. [4] experimentally measured the development of tip leakage flow and loss distribution for a low-pressure axial fan with forward and backward-skewed blades. They found that the circumferentially skewed blades significantly reduce the total pressure loss but increase the circumferential movement of the tip leakage vortex, leading to a more uniform main stream and favourable conditions for delaying stall. Furthermore, the increase in the stall margin of the impeller due to the forward-skewed blades is greater than that of the backward-skewed blades. Vad et al. [5] designed circumferentially skewed blades of an axial fan, and their experimental results showed that the forward-skewed blades enhance the performance of blades by increasing the axial velocity near the tip and by reducing the axial velocity near the lower half of the blade. However, both the total pressure rise and the efficiency decrease. Jin et al. $[6,7]$ experimentally and numerically investigated the performance of a small axial fan with novel circumferentially skewed blades. They found that the forward-skewed blades were able to control the tip leakage flow and low 
energy flow near the hub, expand the stall operating domain, suppress noise, and mitigate inflow turbulence. Moreover, the superiority of the forward-skewed scheme to the backward-skewed one was also observed. Jin et al. [8] used the regression fit method to optimise the design of a mine counter-rotating axial fan. They pointed out that the best skewed angle of the first and second stages are $6.6^{\circ}$ and $-10.08^{\circ}$, respectively, and the total pressure efficiency was increased by $1.64 \%$. Cai et al. [9] conducted experiments on a low-speed and low-pressure axial fan with skewed blades. They found that aerodynamic performance improvement and noise reduction are the greatest if the blade profile centre-of-gravity sits on a curve made up of a straight line followed by an arc, and the arc starting point is located at a relative blade height of 0.4-0.45. The benefits of forward-skewed blades outweighed that of backward-skewed blades, and the aerodynamic efficiency and noise reduction improved when the skewed angle was less than $10^{\circ}$. Ouyang et al. [10] experimentally examined the performance of an axial fan with a T35 impeller with skewed blades of $\theta= \pm 8.3^{\circ}$. They indicated that the forward-skewed blades promote the stall margin by $6 \%$ and reduce noise by $4-5 \mathrm{~dB}$, and a better improvement is observed compared with the backward-skewed blades. Based on the artificial neural network and genetic algorithm, Li et al. [11] used blade skewing to optimise the axial fan rotor, and found that the appropriate skewing of blades in the circumferential direction can improve fan performance, that is, the full pressure rise increased by $3.56 \%$ and stall margin widened by more than $36 \%$ at design conditions. Krömer [12] investigated the effect of combined skewed blades on the performance curves and aerodynamic and aeroacoustic characteristics of a low-pressure axial fan. They found that the aerodynamics and acoustics are strongly influenced by the skewed blades, and that the sound source intensity can be reduced. Zhou et al. [13] utilised the Bezier curve to determine the parameters of the blade meridian of an air-conditioning axial fan and indicated that the flow field is improved and the noise is reduced by $1.1 \mathrm{~dB}$ after blade skewing. Zenger et al. [14] experimentally examined the influence of increased inflow turbulence on the sound generation in forward-and backward-skewed low-pressure axial fans. They found that distorted inflow conditions have a significant impact on the sound emission and the extent of this is strongly related to blade design. Bamberger and Carolus [15] optimized a low-pressure axial fan with highly swept blades $\left(-55^{\circ},+34^{\circ},+55^{\circ}\right.$ at hub, midspan and shroud) for maximal total-to-total fan efficiency and noise reduction at the design point. They found a moderate increase in efficiency at the design point and a reduction in sound emission over the complete operating range. Beiler and Carolus [16] numerically and experimentally conducted an investigation of axial flow fans with skewed blades and found that forward-swept fans exhibited good aerodynamic performance and reduced sound power level.

Similar improvements are also found in other fluid machinery. Liu et al. [17] replaced the blades of a high-speed aviation fuel axial pump with the circumferentially skewed blades and found that skewed blades can effectively suppress the occurrence of a secondary flow, thereby reducing energy loss. $\mathrm{Xu}$ et al. [18] numerically predicted the influence of blade skewing and blade solidity on diffusion and blade loss under the condition of minimum incident loss, and verified the simulation by experiments. They showed that skewed blades can reduce blade loss and improve diffusion efficiency, owing to the low blade solidity. Based on the blade element theory, Starzmann and Carolus [19] established a new design method of blade skewing. The experimental and numerical results showed that the blade skewing technique delays stall. Furthermore, the stall margin expanded by approximately $5 \%$ and the noise reduced by about $3 \mathrm{~dB}$. With respect to the influence of varying the blade pitch angle, some reports have described the effect of an abnormal blade angle on the aerodynamic and acoustic performance of an axial fan [20,21]. Gou et al. [22] studied the effect of the blade pitch angle on the pressure loss of a parallel fan station. They found that an inappropriate blade pitch angle greatly augments air pressure loss and severely degrades efficiency. Hence an unsuitable blade angle should be avoided at any given flow coefficient. In addition, Ye et al. [23] numerically simulated the impact of the blade tip pattern on the performance of a variable-pitch axial flow fan at off-design conditions. They found that the blade tip pattern can improve fan performance by changing the blade pitch of off-design conditions. 
The main parameters of fluid machinery and suggested circumferentially skewed angles mentioned above are summarised in Table 1. It can be seen from Table 1 that the utilisation of circumferentially skewed blades can effectively improve the fan performance and reduce aerodynamic noise. The improvement due to forward-skewed blades is more significant than that due to backward-skewed blades for low-pressure and low-speed axial fans and the best skewed angle should be less than $10^{\circ}$. However, for large-scale variable-pitch axial fans, the features of the fans are different from those in Table 1. For example, the fans adopt high-efficiency 3D twisted blades with large blade spans, operate at a high speed and across a wide range of flow coefficients, and use the rear guide vanes to further promote efficiency. The previous studies mostly focused on the influence of abnormal blade angles on the performance of such fans, whereas few studies on the aerodynamics of the variable-pitch axial fan with circumferentially skewed blades and the adaptability of skewed blades for axial fans at off-design conditions have been conducted. Therefore, in the present study, a single-stage variable-pitch axial fan of type OB- 84 is selected to numerically investigate the influence of skewed blades on the fan's aerodynamic performance and determine the best forward-skewed angle. Then the fan performance at off-design conditions with a different blade pitch is assessed to examine the effect of skewed blades on the aerodynamic performance of the fan. 
Table 1. Comparison of skewed blades in the published literatures and present study.

\begin{tabular}{|c|c|c|c|c|c|}
\hline Rotating Machinery & Main Parameters & Skewed Angle & Suggested Angle & Conclusions & References \\
\hline \multirow{9}{*}{ Axial fan } & $\begin{array}{l}\text { Rotation speed } 1440 \mathrm{r} / \mathrm{min} \text {; hub-tip ratio } 0.35 \text {; } \\
\text { tip diameter } 500 \mathrm{~mm} \text {; tip clearance/span } 1.5 \%\end{array}$ & $\begin{array}{l}\text { Original blade: } 1.27^{\circ} \text {; skewed blade: } \\
\qquad+8.3^{\circ},-8.3^{\circ}\end{array}$ & $+8.3^{\circ}$ & $\begin{array}{l}\text { Reduced the total pressure } \\
\text { loss }\end{array}$ & Li et al. [4] \\
\hline & $\begin{array}{l}\text { Rotation speed } 416 \mathrm{r} / \mathrm{min} \text {; hub-tip ratio } 0.6 \text {; } \\
\text { tip diameter } 2000 \mathrm{~mm} \text {; tip clearance } 7.2 \mathrm{~mm}\end{array}$ & $\begin{array}{c}\text { Skew angle at different fraction of } \\
\text { span: } 0.5 \text { mid:0. } 3^{\circ}, 0.75: 1.6^{\circ} \\
1.00 \text { tip:3. }\end{array}$ & & Improved blade performance & Vad et al. [5] \\
\hline & $\begin{array}{l}\text { Rotor speed } 1440 \mathrm{r} / \mathrm{min} \text {; tip radius } 2475 \mathrm{~mm} \text {; } \\
\text { hub-tip ratio } 0.35 \text {; tip clearance/span } 1 \%\end{array}$ & $+8.3^{\circ},-8.3^{\circ}$ & $+8.3^{\circ}$ & $\begin{array}{l}\text { Reduced noise sources in the } \\
\text { tip clearance region }\end{array}$ & Jin et al. $[6,7]$ \\
\hline & $\begin{array}{l}\text { Rotor speed } 980 \mathrm{r} / \mathrm{min} \text {; hub-tip ratio 0.6; tip } \\
\text { diameter } 1600 \mathrm{~mm}\end{array}$ & $\begin{array}{l}\text { First stage impeller skewed angle } \\
-15^{\circ} \sim 15^{\circ} \text {; secondary impeller angle } \\
-12^{\circ} \sim 12^{\circ}\end{array}$ & $\begin{array}{r}\text { First stage impeller }+6.6^{\circ} \\
\text { secondary impeller }-10.08^{\circ}\end{array}$ & $\begin{array}{l}\text { Increased efficiency by } 1.67 \% \text {; } \\
\text { improved flow in hub }\end{array}$ & Jin $[8]$ \\
\hline & Tip diameter $600 \mathrm{~mm}$; hub-tip ratio 0.4 & $-12^{\circ} \sim 24^{\circ}$ & $8-10^{\circ}$ & $\begin{array}{l}\text { Increased efficiency by } 3.2 \% \text {; } \\
\text { Reduced noise by } 4.5 \mathrm{~dB}\end{array}$ & Cai et al. [9] \\
\hline & $\begin{array}{l}\text { Rotation speed } 1440 \mathrm{r} / \mathrm{min} \text {; hub-tip ratio } 0.35 \text {; } \\
\text { tip diameter } 500 \mathrm{~mm} \text {; tip clearance/span } 1.5 \%\end{array}$ & $\begin{array}{l}\text { Original blade: } 1.27^{\circ} \text {; skewed blade: } \\
\qquad+8.3^{\circ},-8.3^{\circ}\end{array}$ & $+8.3^{\circ}$ & $\begin{array}{l}\text { Increased the stall margin by } \\
6 \% \text {; reduced noise by } 4-5 \mathrm{~dB}\end{array}$ & Ouyang et al. [10] \\
\hline & $\begin{array}{l}\text { Rotation speed } 1500 \mathrm{r} / \mathrm{min} \text {; tip diameter } \\
495 \mathrm{~mm} \text {; tip clearance } 2.5 \mathrm{~mm}\end{array}$ & & & $\begin{array}{l}\text { Reduced sound source } \\
\text { strength }\end{array}$ & Krömer et al. [12] \\
\hline & $\begin{array}{l}\text { Rotation speed } 839 \mathrm{r} / \mathrm{min} \text {; tip diameter } \\
\quad 401 \mathrm{~mm} \text {; hub-tip ratio } 0.25\end{array}$ & & & $\begin{array}{l}\text { Improved flow performance; } \\
\text { reduced noise by } 1.1 \mathrm{~dB}\end{array}$ & Zhou et al. [13] \\
\hline & $\begin{array}{l}\text { Tip diameter } 1500 \mathrm{~mm} \text {; hub-tip ratio } 0.6 \text {; tip } \\
\text { clearance } 4.5 \mathrm{~mm} \text {; rotation speed } 1200 \mathrm{r} / \mathrm{min}\end{array}$ & $\begin{aligned}+1.0^{\circ},+2.0^{\circ}, & +3.0^{\circ},+4.0^{\circ},+6.0^{\circ}, \\
& +8.3^{\circ}\end{aligned}$ & $3.0^{\circ}$ & $\begin{array}{l}\text { Increased total pressure rise } \\
\text { and efficiency; reduced } \\
\text { acoustic noise }\end{array}$ & Present study \\
\hline Axial flow pump & $\begin{array}{l}\text { Rotation speed } 7800 \mathrm{r} / \mathrm{min} \text {; tip diameter } \\
\qquad 70 \mathrm{~mm}\end{array}$ & & & $\begin{array}{l}\text { Suppressed the secondary } \\
\text { flow and reduced energy loss }\end{array}$ & Liu et al. [17] \\
\hline Compressor & $\begin{array}{l}\text { Blade height } 16 \mathrm{~mm} \text {; chord } 128 \mathrm{~mm} \text {; hub-tip } \\
\text { ratio } 1.25 \text {; camber angle } 36.31^{\circ}\end{array}$ & $0^{\circ}, 5^{\circ}, 10^{\circ}, 15^{\circ}, 20^{\circ}, 25^{\circ}, 30^{\circ}$ & & $\begin{array}{l}\text { Reduced loss; recovered } \\
\text { diffusion caused by lower } \\
\text { solidity }\end{array}$ & Xu et al. [18] \\
\hline Water turbine & $\begin{array}{l}\text { Rotation speed } 4000 \mathrm{r} / \mathrm{min} \text {; tip diameter } \\
\quad 400 \mathrm{~mm} \text {; hub-tip ratio } 0.43\end{array}$ & $\begin{array}{c}+15^{\circ},-15^{\circ},-15^{\circ} \text { at hub and }+5^{\circ} \text { at } \\
\text { tip }\end{array}$ & $+15^{\circ}$ & $\begin{array}{l}\text { Delayed stall occurrence; } \\
\text { increased stall margin; } \\
\text { reduced noise by } 3 \mathrm{~dB} \text {. }\end{array}$ & $\begin{array}{l}\text { Starzmann and } \\
\text { Carolus [19] }\end{array}$ \\
\hline
\end{tabular}




\section{Computational Model}

\subsection{Fan Model}

As shown in Figure 1, a single-stage variable-pitch axial fan of type OB-84 is selected to investigate the effect of skewed blades on the aerodynamic performance of the fan. The fan consists of four parts: bell mouth, impeller, guide vane, and diffuser. The rotating blades are 3D twisted blades with an asymmetric airfoil of NACA 3506 as the basic profile. The main parameters are listed in Table 2.

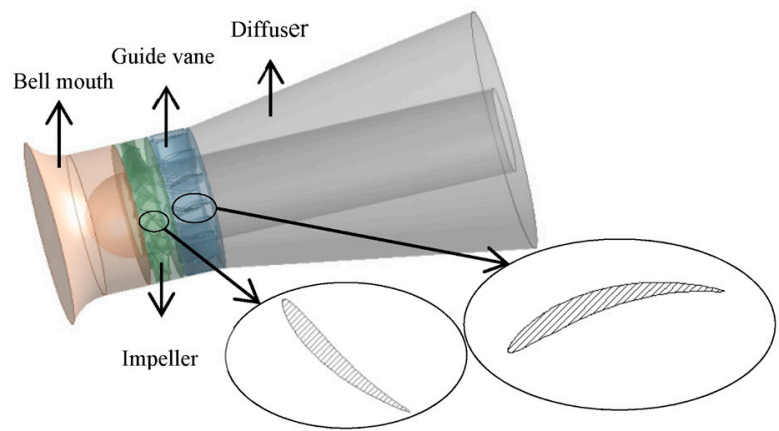

(a)

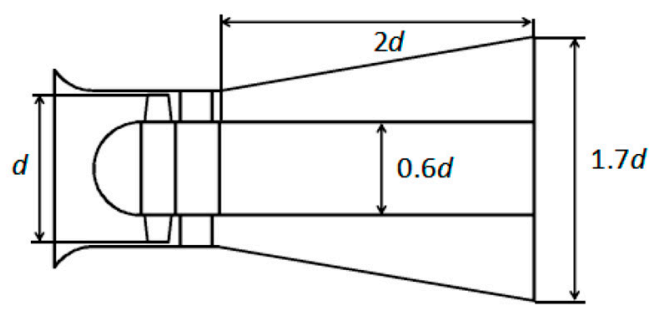

(b)

Figure 1. Model of the axial flow fan of type OB-84. (a) physical model; (b) dimensions of the fan.

In this study, axial fans with conventional radial blades as the original blades and with circumferentially forward-skewed blades are designed by ANSYS Gambit software (GAMBIT 2.4.6, ANSYS Inc., Canonsburg, PA, USA) to provide the input geometry for ANSYS Fluent 15.0 CFD. The schematic of the blades is shown in Figure 2. The blade pitch angle $\beta$ is defined as the angle between the tangent of the airfoil section and the direction perpendicular to the axis of the fan, as shown in Figure 3a. The skewed angle $\theta$ is incrementally increased to $\theta=1.0^{\circ}, 2.0^{\circ}, 3.0^{\circ}, 4.0^{\circ}$, $6.0^{\circ}$, and $8.3^{\circ}$, to lie in the range recommended by References [4,6-10] (presented in Table 1). $\theta=0^{\circ}$ represents the original blade. The circumferentially skewed blade is redesigned to keep the original airfoil shape unchanged, and the circumferentially skewed angle is achieved by changing the centre of gravity stacking line. The centre of gravity stacking line of the original blade and circumferentially forward-skewed blade, and the diagram of skewed angle are shown in Figure 3b. The centre of gravity stacking line is a straight line from the blade root to point $B$ followed by an arc from point $B$ to the blade tip, where the demarcation point $B$ is located at $40 \%$ of the relative blade height. The angle $\theta$ between the line $O F$ from hub axis to the end of the stacking line and the stacking line $A R$ of the original blade is defined as the skewed angle, and the direction of the circumferentially forward-skewed angle is in the rotation direction.

Table 2. Design parameters of the fan.

\begin{tabular}{cc}
\hline Number of impeller blades and guide vanes & 14,15 \\
Diameter at the tip, $\mathrm{mm}$ & 1500 \\
Hub-tip ratio & 0.6 \\
Tip clearance, $\mathrm{mm}$ & 4.5 \\
Rotation speed, $\mathrm{r} \cdot \mathrm{min}^{-1}$ & 1200 \\
Volumetric flow rate, $\mathrm{m}^{3} \cdot \mathrm{s}^{-1}$ & 37.14 \\
Total pressure rise, $\mathrm{Pa}^{\circ}$ & 2348 \\
Installation angle, & \\
\hline
\end{tabular}




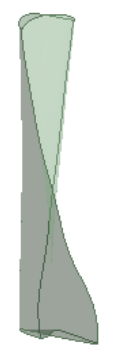

(a)

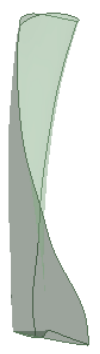

(b)

Figure 2. Diagram of blades. (a) original blade; (b) circumferentially forward-skewed blade.

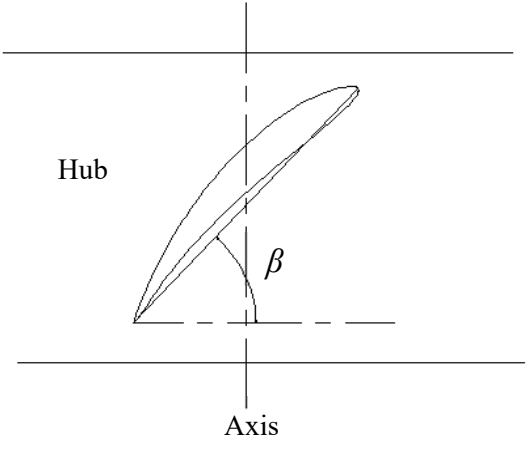

(a)

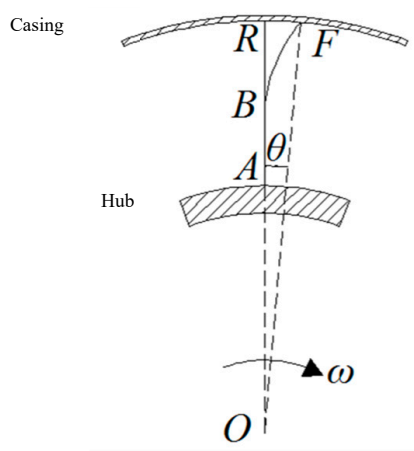

(b)

Figure 3. (a) Sketch of blade pitch angle; (b) sketch of stacking line and circumferentially forward-skewed angle.

\subsection{Meshing}

Due to the complexity of the flow at the blade tip and around the airfoil, a multiblock topology meshing scheme is applied in this study. The mesh generation utilises hybrid meshes for the whole computational domain and the mesh near the tip clearance is clustered. The computational mesh in the tip domain uses tetrahedral cells, and the suction/pressure surfaces adopt hexahedral cells. A size function is applied to mesh the impeller region and to densify the meshes in the tip clearance instead of the boundary layer model. It is achieved by meshing the blade tip, as a priority and then meshing from the blade tip to both the pressure and suction surfaces. After all blade surfaces are meshed, the size function is employed again to mesh the impeller.

In this study, integral parameters including the total pressure rise and the stage total-to-total efficiency (hereinafter referred to as efficiency), are selected to verify the mesh independence and to compare simulated and experimental results. Perhaps flow parameters such as the velocity at the blade tip, flow angles at the rotor and vane exits, are more sensitive than integral parameters. However, changes in these parameters are finally reflected with changes in integral parameters. Therefore, the verification method using integral parameters is widely applied in many researches [21,24-27]. To verify the mesh independence, fans with mesh numbers of 3.82, 4.26, 4.65, 5.33 and 5.56 million are simulated in this study, as shown in Table 3. Considering the calculation accuracy and computational duration, the fan with a mesh number of 5.33 million is selected.

Table 3. Validation of mesh independence.

\begin{tabular}{cccc}
\hline Meshing Number/million & Total Pressure Rise/Pa & Efficiency/\% & Time/h \\
\hline 3.82 & 2316.43 & 81.052 & 9.8 \\
4.26 & 2325.95 & 81.237 & 10.2 \\
4.65 & 2333.55 & 81.506 & 10.6 \\
5.33 & 2333.82 & 81.509 & 11.5 \\
5.56 & 2333.96 & 81.510 & 12.6 \\
\hline
\end{tabular}




\subsection{Numerical Method}

Fluent software is selected to simulate the fan with the original and forward-skewed blades. The main settings are listed as follows:

(1) Governing equation: the continuity equation and 3D steady Reynolds-averaged Navier-Stokes (RANS) equation are used; the convection term, diffusion term, and turbulent viscosity are all discretised by the second-order upwind scheme [28,29].

(2) Turbulence model: considering the complex internal flow dynamics of axial flow fans and the evolution of different vortices, including the passage vortex, tip leakage vortex, scraping vortex, and wakes [30-34], the Realisable $k-\varepsilon$ model that effectively simulates the complex flow in the tip clearance and the rotational motion is applied $[1,2,19,35]$. The SIMPLE algorithm is used to achieve the coupling of velocity and pressure [36]. The MRF (multiple reference frame) model, considering the interference at the interface between the rotating and stationary domains, is an efficient path to simulate steady flows in a short computation time; it is widely utilized in the fluid machinery applications $[2,19]$. Considering the complexity of data processing and the time required for the computation, the MRF model is employed for the coupling between the impeller and the casing in this study.

(3) Domain division: four regions are involved. The impeller is defined as the rotating region with a rotating speed and rotation direction, and the bell mouth, guide vane, and diffuser are classified as the static region.

(4) Boundary conditions: the inlet surface of the bell mouth and the outlet surface of the diffuser are referred to as the inlet and outlet of the entire flow field, respectively, using the velocity inlet and outflow outlet conditions. The inlet velocity is determined by the corresponding flow rate under a specific operating point and the outlet condition is uniformly set to free outflow. The turbulent kinetic energy and the turbulent dissipation rate of the inlet surface are calculated by substituting the average flow velocity and the characteristic length of the inlet cross-section into the empirical formula [37]. The surfaces of the impeller blade and hub are treated as the rotating surface, and the rest are treated as the static surfaces. The interface between adjacent regions is defined as the Interface, which is used for the coupling of data transmission and exchange. All walls adopt the no-slip boundary and the near wall region adopts a standard wall function.

Assume that air is incompressible; the heat transfer between the air and the wall/blade is neglected and then physical parameters are constant; the effects of gravity and wall roughness are ignored $[2,20,23,38]$. The iteration steps are set to be 3000 . The simulation is converged when the residuals of the parameters, including velocity in all directions of the inlet and outlet, $k$, and $\varepsilon$, are less than $10^{-4}$.

\subsection{Verification of Simulation}

Before simulating fan performance with the circumferential skewed blades, the present study compares the simulated and experimental results including the total pressure rise and efficiency of the original fan in the range of $Q_{v}=33.31-46.63 \mathrm{~m}^{3} \cdot \mathrm{s}^{-1}$, as shown in Figure 4 . The experimental results and other detailed information of the fan can be found in the literature [39]. The comparison shows that the average relative deviation of the total pressure rises and efficiency is $2.69 \%$ and $1.04 \%$, respectively, and the relative deviation at the design condition is $1.88 \%$ and $1.80 \%$, respectively, indicating the reliability of the present simulation and its feasibility in reflecting the actual operating condition of the fan. 


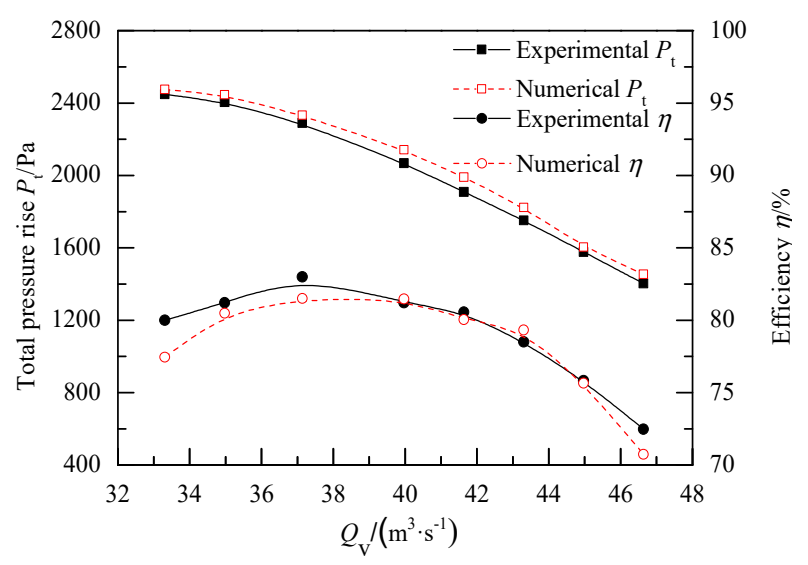

Figure 4. Comparison of simulated and experimental results.

\section{Results and Discussion}

\subsection{Fan Performance}

In this study, to speed up the research process, the range of skewed angles is firstly based on the investigated range from the available reports $[4,6-10]$, as indicated in Table 1 . Then the best skewed angle within the present flow rates is determined by the variations in the total pressure rise and efficiency of the fan. Figure 5 depicts the effect of the forward-skewed angle on the total pressure rise and efficiency. As indicated in Figure 5a, the variation in the total pressure rise with the skewed angle $\theta$ is characterised by a parabola at the design flowrate of $Q_{v}=37.14 \mathrm{~m}^{3} \cdot \mathrm{s}^{-1}$, and the total pressure rise is significantly improved at $\theta=1.0-4.0^{\circ}$, especially at $\theta=2.0$ and $3.0^{\circ}$. The maximum gain is obtained at $\theta=3.0^{\circ}$ with the total pressure rise increased by approximately $3 \%$ and efficiency increased by $0.16 \%$ compared those of the original fan. At $\theta>4.0^{\circ}$, the total pressure rise is lower than the original one. The efficiency variation is roughly illustrated with a $\sim$ curve, and the relative reduction in the range of $\theta=2.0-3.0^{\circ}$ is less than that at other angles compared to the original fan. Additionally, the average relative reduction is only $0.19 \%$ in the range $\theta=2.0-3.0^{\circ}$. Considering the influence of the forward-skewed angle on the total pressure rise and efficiency, the best forward-skewed angle at the design flow rate is $\theta=2.0-3.0^{\circ}$, which is consistent with the results in Reference [40].

The influence of the forward-skewed angle on fan performance at different flow rates is presented in Figure 5b,c. At $\theta=1.0-4.0^{\circ}$, the total pressure rise is increased; at $\theta>4.0^{\circ}$, the total pressure rise at all working conditions is lower than that of the original fan. The influence on efficiency is as follows: at flow rates less than $37 \mathrm{~m}^{3} \cdot \mathrm{s}^{-1}$, the best improvement in efficiency is observed with $\theta=3.0^{\circ}$, but in the intermediate and large flow rate range, the best improvement is found with $\theta=1.0^{\circ}$ and $\theta=2.0^{\circ}$, respectively. Figure $5 b, c$ show that the best skewed angle is distinctly different at the different flow rate ranges. According to the changes in the total pressure rise and efficiency, the changes mentioned above are roughly summarised as follows: (1) in the range $Q_{v}=33.31-39.31 \mathrm{~m}^{3} \cdot \mathrm{s}^{-1}$, the optimal improvement in performance is obtained with $\theta=3.0^{\circ}$; (2) for $Q_{v}=39.31-44.1 \mathrm{~m}^{3} \cdot \mathrm{s}^{-1}$, the best skewed angle is $\theta=1.0^{\circ}$; (3) for $Q_{v}=44.1-46.61 \mathrm{~m}^{3} \cdot \mathrm{s}^{-1}, \theta=2.0^{\circ}$ is preferred. The total pressure rise in the three flow rate ranges increases on average by $1.94 \%, 5.09 \%$, and $7.31 \%$, respectively, and efficiency changes by $-0.19 \%,-0.08 \%$, and $0.26 \%$, respectively. A comparison shows that, the scheme of $\theta=1.0^{\circ}$ presents better performance over a wide range of large flow rates. However, at the design flow rate and the left side, the scheme of $\theta=3.0^{\circ}$ displays the best performance compared with other skewed angles. Considering that axial fans mostly operating at the design point and left side owing to their excessive margins at the design stage [1], the skewed angle of $\theta=3.0^{\circ}$ is the best selection in practical applications. The following study is carried out with the best forward-skewed angle of $\theta=3.0^{\circ}$. 


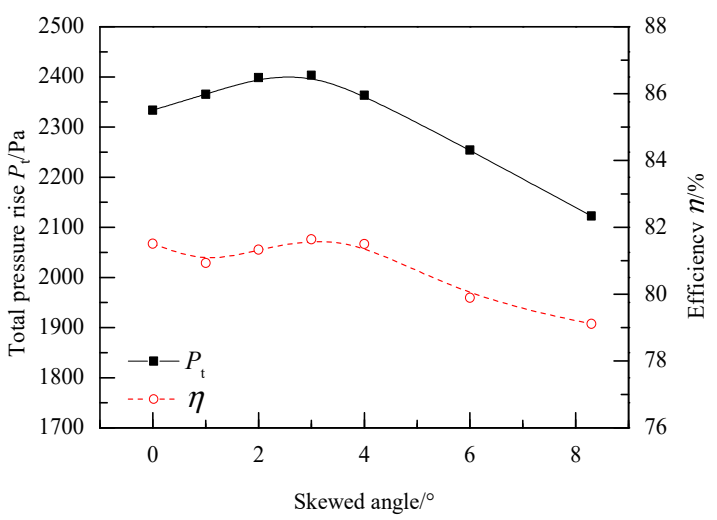

(a)

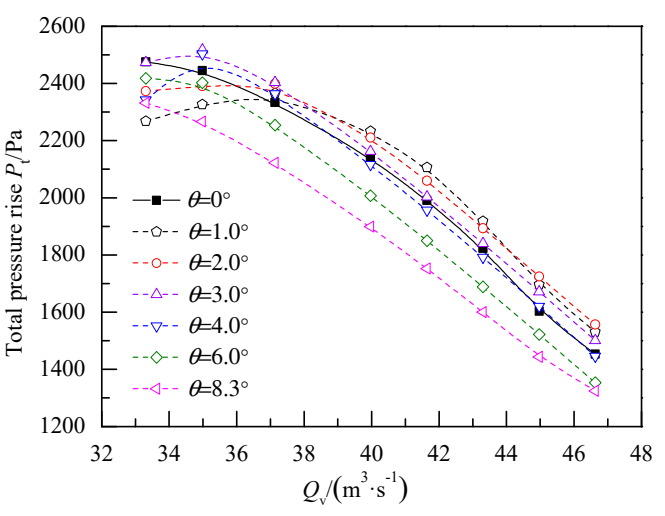

(b)

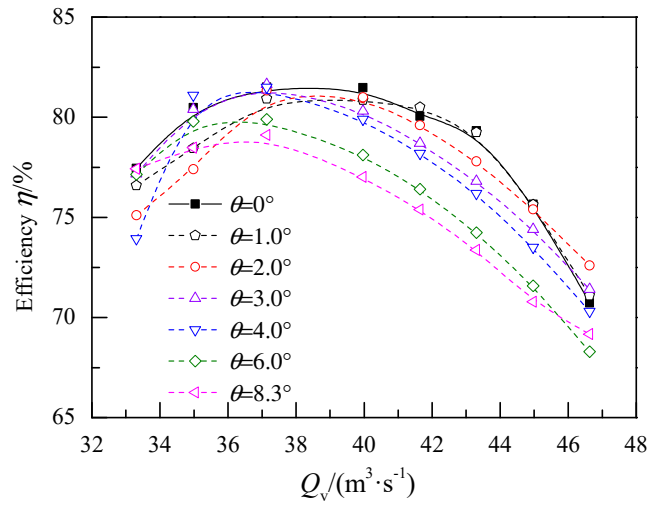

(c)

Figure 5. Effect of circumferentially forward-skewed blades on fan performance. (a) design condition; (b) variation in total pressure rise; (c) variation in efficiency.

In practical operation, blade pitch angle is changed to follow the fan load [3]. The performance curves $\left(\beta=29^{\circ}, 32^{\circ}\right.$, and $\left.35^{\circ}\right)$ provided by the manufacturer are within the normal working range exclusive of the stall range [39]. The fan performance is modelled off-design conditions to examine the performance of the $\theta=3.0^{\circ}$ skewed blades at a different blade pitch angle.

Figure 6 illustrates the variation in fan performance at $\beta=29^{\circ}, 32^{\circ}$, and $35^{\circ}$. For the original fan with $\theta=0^{\circ}$, as the blade pitch angle increases, the total pressure rise curve shifts towards higher flow rates. That is, the total pressure rise increases with blade pitch angle at the same flow rate. And for a given total pressure rise, more flow rate is delivered by increasing the blade pitch angle. The efficiency curve is characterized by unique maxima, and these maxima moves to higher flow rates as the blade pitch angle increases, but the maximum efficiency at $\beta=29^{\circ}$ and $35^{\circ}$ is less than that at $\beta=32^{\circ}$.

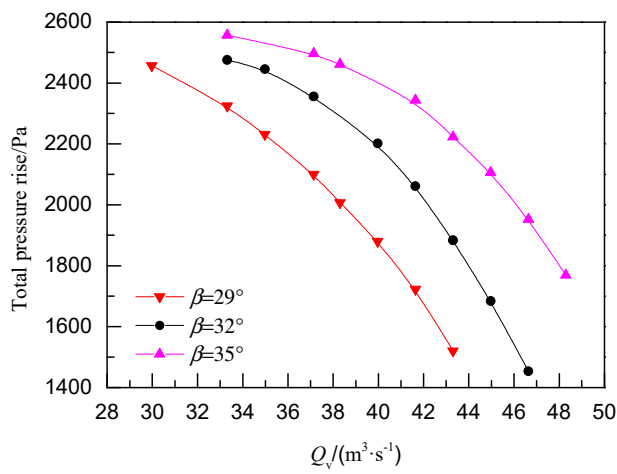

(a)

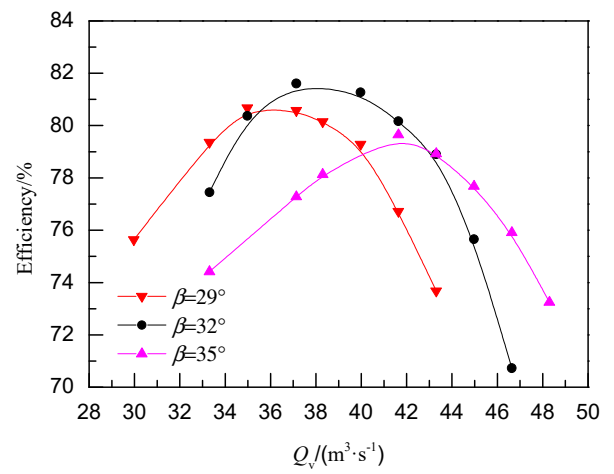

(b)

Figure 6. Performance curve of original fan at $\beta=29^{\circ}, 32^{\circ}$ and $35^{\circ}$. (a) total pressure rise; (b) efficiency. 
Figure 7 illustrates the effect of forward-skewed blades on fan performance with three blade pitch angles of $\beta=29^{\circ}, 32^{\circ}$, and $35^{\circ}$. For the fan with the forward-skewed blade of $\theta=3.0^{\circ}$, the effect on fan performance is distinctly different at each blade pitch angle. The average changes in the total pressure rise and efficiency over different flow rate ranges are listed in Table 4. With blade skewing, the change in the total pressure rise at the highest efficiency point for $\beta=29^{\circ}, 32^{\circ}$ and $35^{\circ}$ is $-0.55 \%$, $2.99 \%$, and $-0.53 \%$, respectively, and the corresponding change in efficiency is $1.39 \%, 0.16 \%$, and $2.11 \%$. The results show that at $\beta=32^{\circ}$, the total pressure rise across the fan with $\theta=3.0^{\circ}$ is improved across most of the flow rate range, but efficiency is slightly reduced; at $\beta=29^{\circ}$, the total pressure rise is decreased across the full range of volumetric flow rate, while efficiency is increased over most of the $Q_{v}$ range. However, at $\beta=35^{\circ}$, the performance improvement is distinctly limited to large flow rates. It can be observed from the above analysis that the optimal forward-skewed angle of $\theta=3.0^{\circ}$ selected from the design condition is not effective for improving the total pressure rise at $\beta=29^{\circ}$ and $35^{\circ}$, but is useful for improving the efficiency, namely, $\theta=3.0^{\circ}$ forward-skewed blades can provide good fan performance at design and off-design conditions.

To further clarify the effect of forward-skewed blades on the internal dynamics of the fan with and without blade skewing, the characteristics of representative parameters under the three blade pitch angles are explored. These characteristics include the distribution of the axial velocity, the total pressure rise and diffuser coefficients along the blade height, and the distribution of static pressure, specific entropy production rate and specific turbulent kinetic energy of the blade surface.

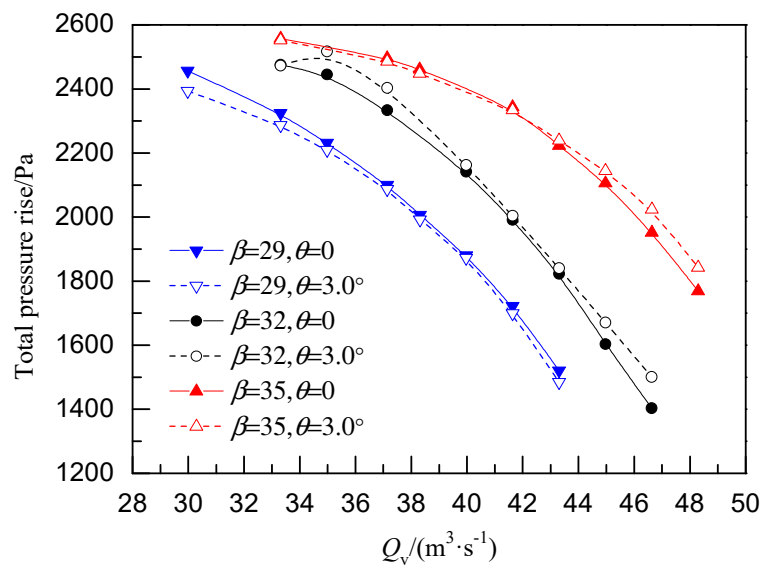

(a)

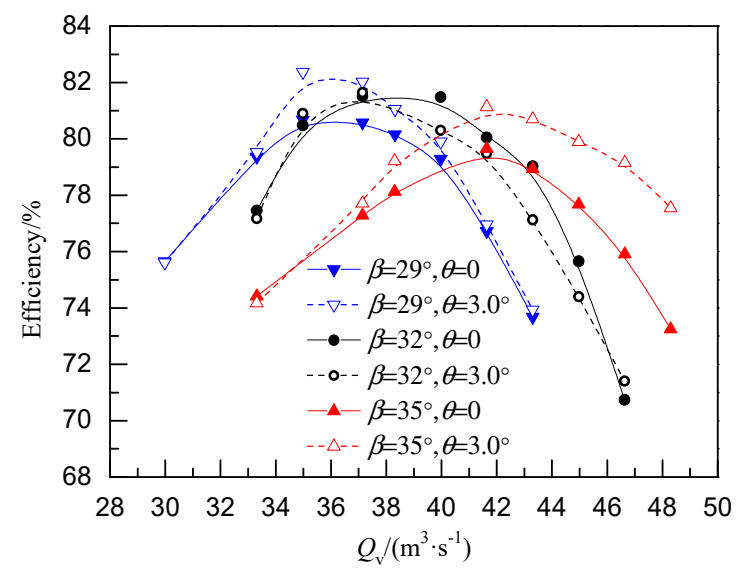

(b)

Figure 7. Effect of forward-skewed blades on fan performance with different blade pitch angles. (a) total pressure rise; (b) efficiency.

Table 4. Effect of forward-skewed blades on total pressure and efficiency at three blade pitch angles.

\begin{tabular}{ccccc}
\hline Blade Angle $^{\circ}$ & $Q_{v} /\left(\mathbf{m}^{\mathbf{3}} \cdot \mathbf{s}^{-\mathbf{1}}\right)$ & Variation of $\boldsymbol{P}_{\mathbf{t}} / \%$ & $Q_{v} /\left(\mathbf{m}^{\mathbf{3}} \cdot \mathbf{s}^{-\mathbf{1}}\right)$ & Variation of $\eta / \%$ \\
\hline \multirow{2}{*}{$\beta=29$} & \multirow{2}{*}{$29.98-43.3$} & -1.34 & $29.98-31.00$ & -0.04 \\
& & & $31.00-43.30$ & 0.95 \\
\hline \multirow{2}{*}{$\beta=32$} & \multirow{2}{*}{$33.31-33.50$} & -0.11 & $33.31-34.00$ & -0.37 \\
\cline { 2 - 5 } & \multirow{2}{*}{$33.50-46.63$} & 2.23 & $34.00-37.14$ & 0.34 \\
\hline \multirow{2}{*}{$\beta=35$} & $33.31-41.64$ & -0.38 & $37.14-46.00$ & -1.55 \\
& $41.64-48.30$ & 2.59 & $33.31-35.00$ & 0.95 \\
\hline
\end{tabular}




\subsection{Distribution of Axial Velocity Along Blade Height}

The axial velocity determines the volumetric flow rate through the impeller. Figure 8 shows the distribution of the axial velocity $v_{a}$ along the blade height at the exit section of the impeller for the original and forward-skewed blades at the three blade angles. The relative blade height of the impeller is defined as $R=\left(r-r_{h}\right) /\left(r_{t}-r_{h}\right)$, where $r$ is the radial blade height of the impeller, and $r_{h}$ and $r_{t}$ are the hub and tip radius, respectively. After the simulation converged, the value of axial velocity is taken as the area-weighted average at a specific height on the exit section of the impeller in Fluent. It should be pointed out that flow conditions of Figure $8 \mathrm{a}-\mathrm{c}$ are different. This is because that the flow rate in Figure 8 is the flow rate corresponding to the highest efficiency point at each blade pitch angle. That is, the flow rate at $\beta=29^{\circ}, 32^{\circ}$ and $35^{\circ}$ is $34.98 \mathrm{~m}^{3} \cdot \mathrm{s}^{-1}, 37.14 \mathrm{~m}^{3} \cdot \mathrm{s}^{-1}$ and $41.64 \mathrm{~m}^{3} \cdot \mathrm{s}^{-1}$, respectively, as indicated in Figure $7 \mathrm{~b}$. Therefore, with increasing blade pitch angle, the flow rate increases, then the axial velocity of the airflow along the entire blade height is raised according to the flow continuity. This results in the visibly different profiles of the axial velocity at each blade pitch angle.

Inspection of Figure 8 indicates that the main through flow area of the impeller is $R=0.5-0.9$. The maximum axial velocity of the forward-skewed fan is close to that of the original one, and both of them are located at $R=0.8$. By increasing blade pitch angle, the axial velocity along the entire blade height is raised, which shows that increasing the blade pitch angle can increase the work and flow rates [3]. Additionally, in the range $R=0-0.8$, the axial velocity increases with increasing blade pitch angle. An inflection point occurs at $R=0.5$ for $\beta=32^{\circ}$ and $35^{\circ}$. The axial velocity, however, increases linearly for $\beta=29^{\circ}$. With skewed blades, an increase in axial velocity is observed over the range $R=0-0.65$ with $\beta=29^{\circ}$ and over the range $R=0-0.8$ with $\beta=32^{\circ}$ and $35^{\circ}$, and this increment is greater with increasing blade pitch angle, especially near the blade root. This is possibly due to the fact that with blade skewing, the upper airflow is transferred towards the middle and lower parts along the blade surface, then the axial velocity increases near the blade root. Compared with a small blade angle of $\beta=29^{\circ}$, the blade skewing with $\beta=32^{\circ}$ or $35^{\circ}$ causes more airflow in the middle and lower parts of the flow passage, leading to the higher axial velocity near the blade root. Close to the casing, at all three blade pitch angles, the axial velocity decreases at $\theta=3.0^{\circ}$ compared with at $\theta=0^{\circ}$, especially near the blade tip, and the axial velocity reduces significantly with an increase in blade pitch angle. The above features indicate that, at the blade pitch angles of $29^{\circ}, 32^{\circ}$ and $35^{\circ}$, the forward-skewed blade can mitigate the tip leakage and delay the occurrence of separation flow in the blade root, resulting in a more stable flow in the root and favourable conditions that increase the stall margin $[8,10]$. Moreover, with increasing blade pitch angle, the effect of the forward-skewed blade on the tip leakage is enhanced and the flow in the root region is more stable.

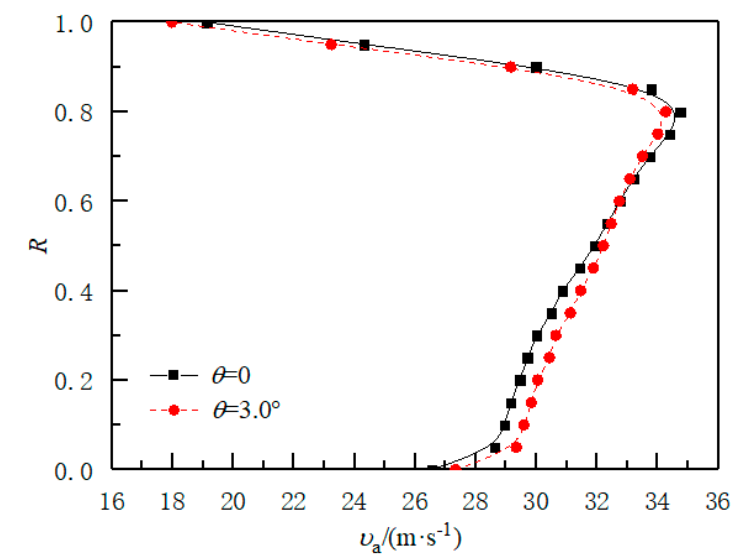

(a)

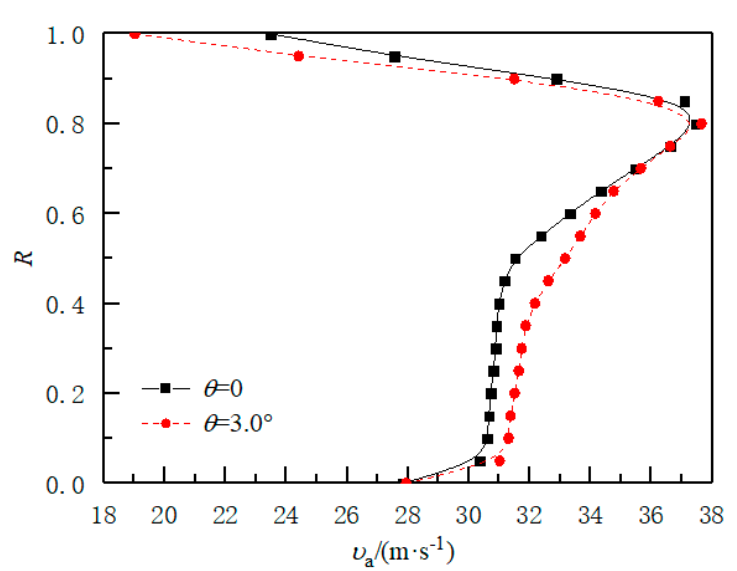

(b)

Figure 8. Cont. 


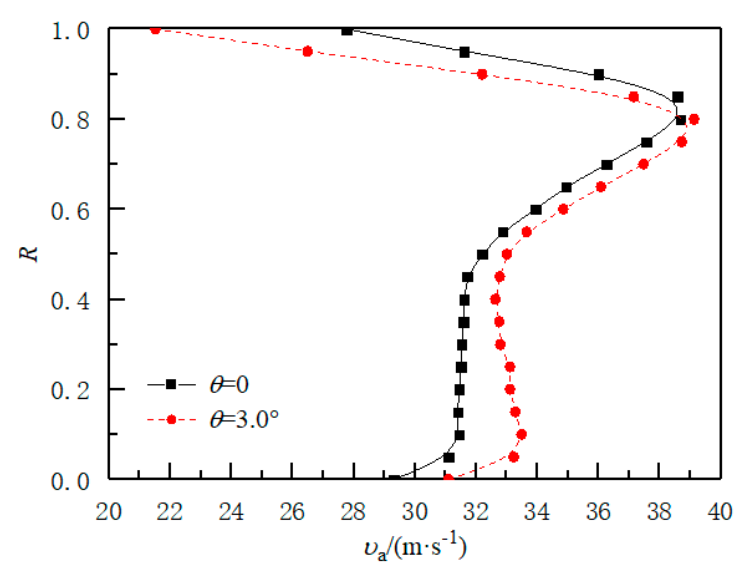

(c)

Figure 8. Distribution of the axial velocity along the blade height. (a) $\beta=29^{\circ}$ and $Q_{v}=34.98 \mathrm{~m}^{3} \cdot \mathrm{s}^{-1}$; (b) $\beta=32^{\circ}$ and $Q_{v}=37.14 \mathrm{~m}^{3} \cdot \mathrm{s}^{-1}$; (c) $\beta=35^{\circ}$ and $Q_{v}=41.64 \mathrm{~m}^{3} \cdot \mathrm{s}^{-1}$.

\subsection{Distribution of Axial Velocity at Different Blade Heights}

To examine the axial velocity changes passing the impeller, Figures 9 and 10 present the axial velocity distribution of the airflow at the cross section of $R=0.5$ and 1.0 of the impeller in the region of rotating blades and guide vanes. The vertical black lines in the figures are the interface projections of different components of the fan. At different blade pitch angles, the axial velocity distribution is qualitatively similar. As the circumferential velocity at $R=1.0$ is higher than that at $R=0.5$, it has a significant impact on the localized flow and downstream, leading to more disordered contours, as shown in Figure 10. That is, the mixing of the upstream and downstream in Figure 10 appears more apparently compared to the mixing in Figure 9. The different features with and without blade skewing can be summarized as follows: in Figure 9, at all the three blade pitch angles, the high-velocity zone on the blade suction side and the medium-velocity zone from the pressure surface to the impeller exit have a larger extent at $\theta=3.0^{\circ}$ (as indicated with $\mathrm{A}$ ), and the same is true for the leading edge on the suction surface of the vanes (indicated with B). In Figure 10, the velocity distribution in the tip section of $R=1.0$ is much more complicated than that of $R=0.5$. Figure 10 shows a reduced high-velocity zone (indicated with $\mathrm{C}$ ), and a reduced lower-velocity zone (indicated with $\mathrm{D}$ ) at $\theta=3.0^{\circ}$ compared to $\theta=0^{\circ}$. A similar velocity change in the guide vane is exhibited as for $\theta=29^{\circ}$, and the maximum axial velocity with blade skewing is lower than that for $\theta=0^{\circ}$ with $\beta=35^{\circ}$ (indicated with E). It can be noted that, at the three blade pitch angles, the axial velocity at $R=0.5$ is significantly increased for $\theta=3.0^{\circ}$, but the velocity at $R=1.0$ is reduced, which agrees with the results of the axial velocity radial profiles shown in Figure 8. 


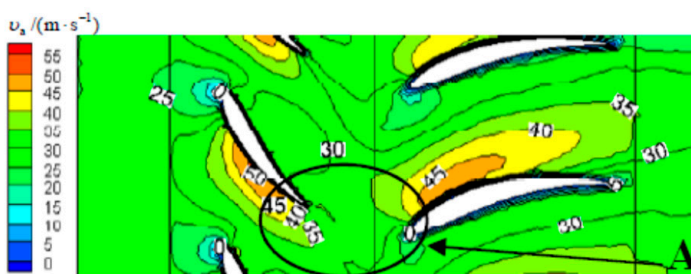

(a)

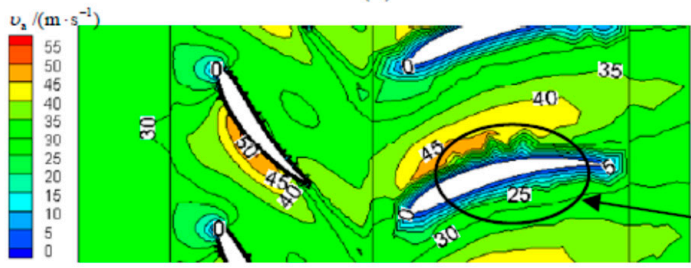

(c)

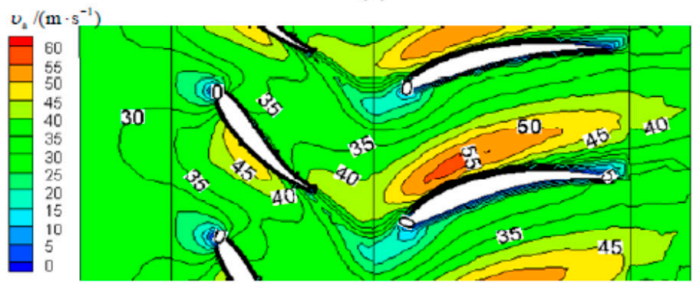

(e)

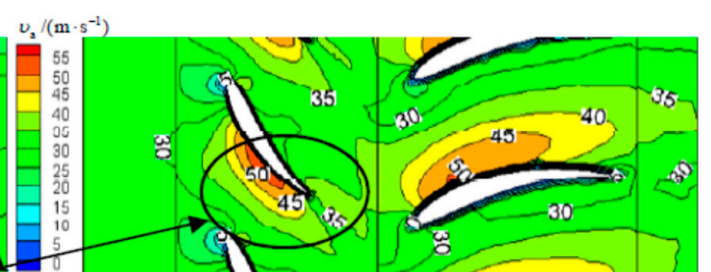

(b)

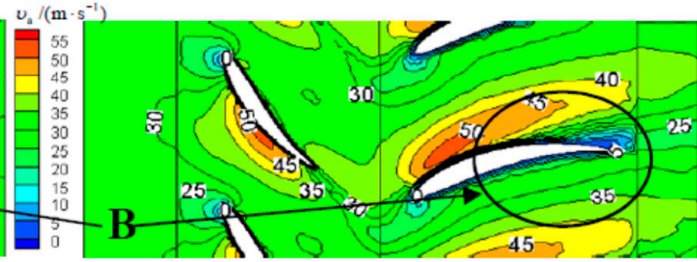

(d)

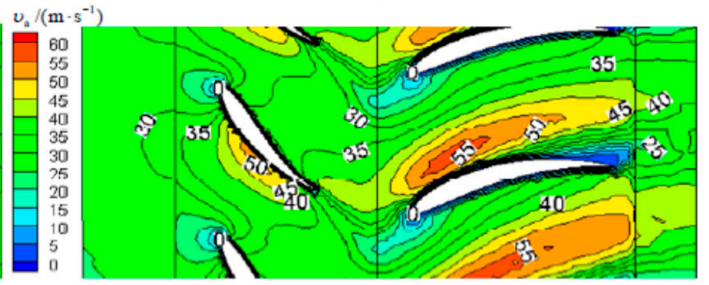

(f)

Figure 9. Distribution of the axial velocity at the section of $R=0.5$. (a) $\beta=29^{\circ}, \theta=0^{\circ}$; (b) $\beta=29^{\circ}$, $\theta=3.0^{\circ}$; (c) $\beta=32^{\circ}, \theta=0^{\circ}$; (d) $\beta=32^{\circ}, \theta=3.0^{\circ}$; (e) $\beta=35^{\circ}, \theta=0^{\circ}$; (f) $\beta=35^{\circ}, \theta=3.0^{\circ}$.
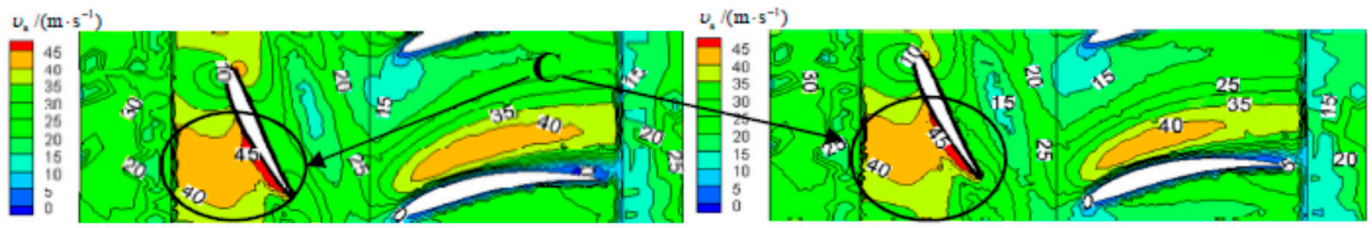

(a)

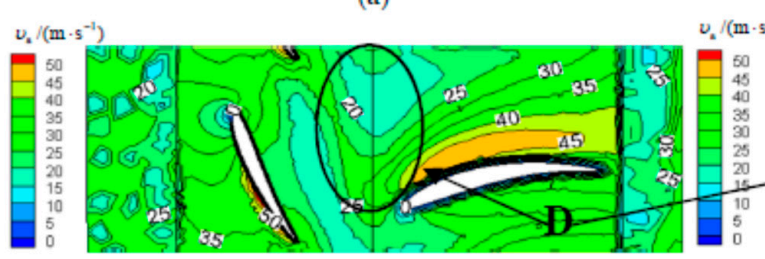

(c)

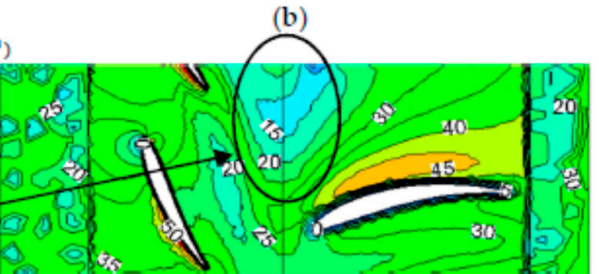

(d)

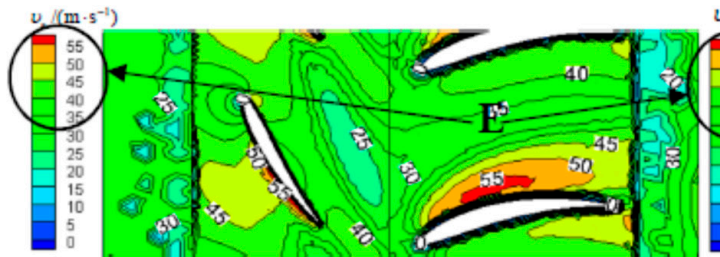

(e) $u_{\mathrm{s}} /\left(\mathrm{m} \cdot \mathrm{s}^{-1}\right)$

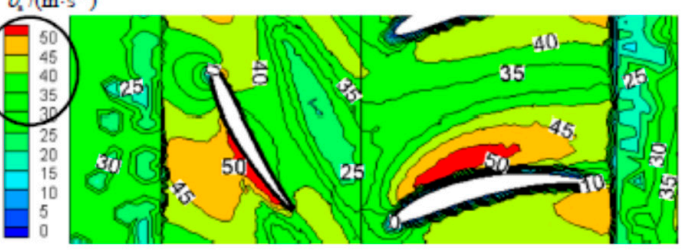

(f)

Figure 10. Distribution of the axial velocity at the section of $R=1$. (a) $\beta=29^{\circ}, \theta=0^{\circ}$; (b) $\beta=29^{\circ}$, $\theta=3.0^{\circ}$; (c) $\beta=32^{\circ}, \theta=0^{\circ}$; (d) $\beta=32^{\circ}, \theta=3.0^{\circ}$; (e) $\beta=35^{\circ}, \theta=0^{\circ}$; (f) $\beta=35^{\circ}, \theta=3.0^{\circ}$.

\subsection{Distribution of Static Pressure on Blade Surface}

The distribution of the static pressure on the blade surface reflects the load on it [41]. Figure 11 shows the distribution of the static pressure on the suction and pressure surfaces (SS and PS), where Le and Te denotes the leading edge and trailing edge, respectively. The static pressure in this study is the pressure relative to the ambient pressure. It can be seen that, for all cases, the blade surface static pressure distribution has the following common trends: a high-pressure zone is formed at the leading edge and at 
the middle upper part near the trailing edge of PS, and a low-pressure zone is generated at the middle and upper parts close to the leading edge of SS owing to localised flow separation [22]. At the blade tip, a blade tip leakage flow forms owing to the pressure difference between the suction/pressure surfaces [17,34,42,43], and the occurrence of leakage vortices near the tip clearance results in the formation of a low static pressure zone at the tip region $[23,32]$. With the skewed blades, the area covered by the static pressure gradient near the trailing edge of PS visibly reduces, as indicated with A, for example, the pressure distribution area greater than $1000 \mathrm{~Pa}$ is significantly reduced; for $\beta=32$ and $35^{\circ}$, the static pressure maximum significantly reduces from $3000 \mathrm{~Pa}$ to $2000 \mathrm{~Pa}$. The area covered by the static pressure gradient of the low-pressure zone of SS expands, and even a negative low-pressure zone appears, as indicated with B. This shows that the forward-skew blades aggregate the flow separation on the suction surface. The possible reason is that with blade skewing, the airflow in the upper part of the blade is displaced towards the middle and lower parts, resulting in the axial velocity reduction in the middle and upper parts, which increases the relative angle of incidence and leads to rotor blade tip leading edge stall. At $\beta=29^{\circ}, 32^{\circ}$ and $35^{\circ}$, the $\mathrm{PS} / \mathrm{SS}$ pressure difference at the tip for $\theta=3.0^{\circ}$ is lower than that for $\theta=0^{\circ}$, indicating that forward-skewed blades can reduce the driving force for generating the tip leakage at all three different pitch angles, thereby reducing the tip leakage flow.

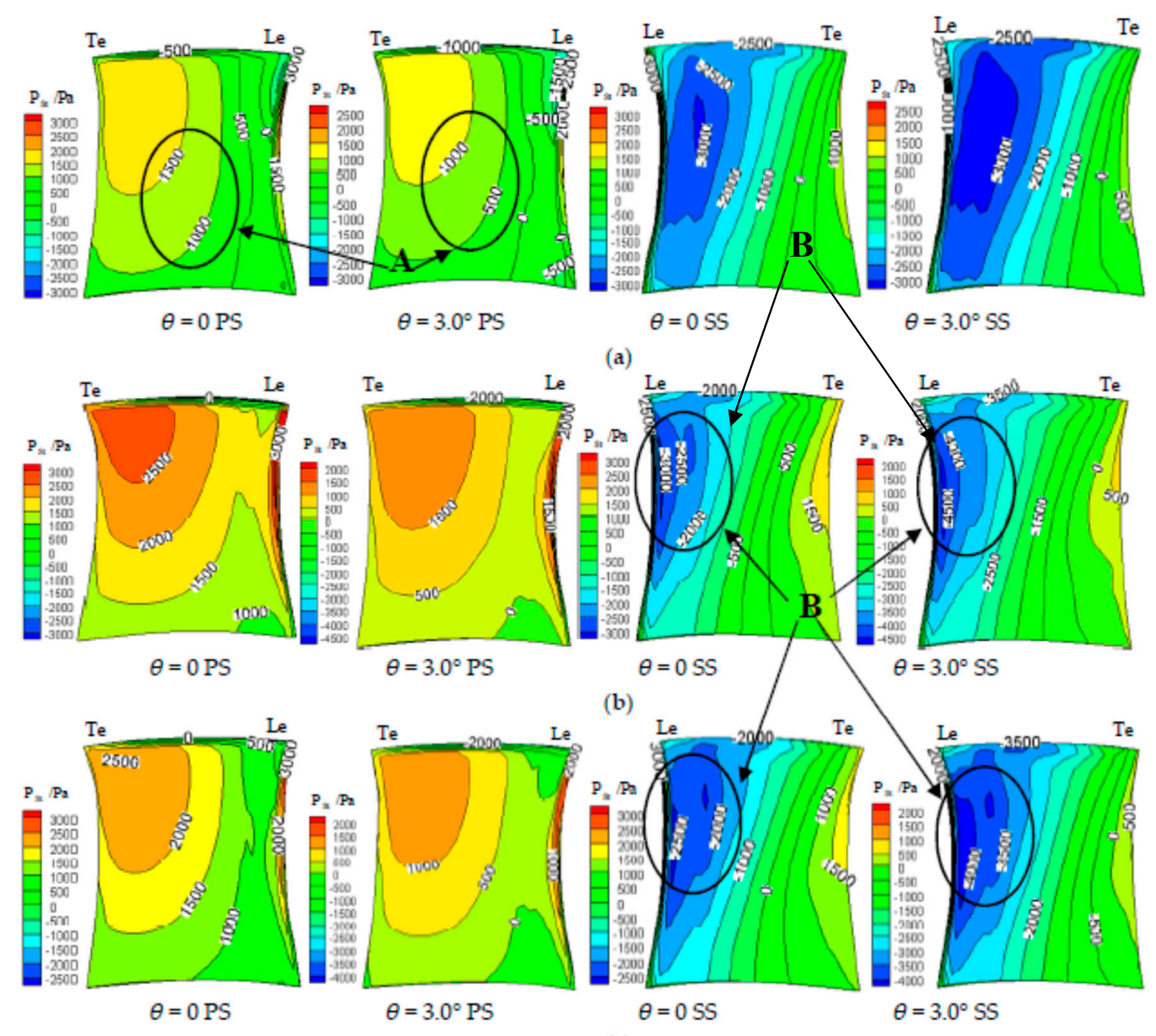

(c)

Figure 11. Distribution of the relative static pressure at the blade surfaces. (a) $\beta=29^{\circ}$; (b) $\beta=32^{\circ}$; (c) $\beta=35^{\circ}$.

\subsection{Distribution of Total Pressure Rise and Static Pressure Recovery Coefficients}

The total pressure rise coefficient of the impeller and the diffuser static pressure recovery coefficient of the guide vane can be used to characterise the stage performance. Figure 12 shows the predicted distribution of the total pressure rise coefficient and of the static pressure recovery coefficient along the 
blade height for the cases $\theta=0^{\circ}$ and $3.0^{\circ}$. The total pressure rise coefficient is defined as $\Phi=2\left(P_{2 t}\right.$ $\left.-P_{1 t}\right) / \rho u^{2}$, and the static pressure recovery coefficient is defined as $D=2\left(P_{2 s}-P_{1 s}\right) / \rho u^{2}$, where $P_{1 t}$ and $P_{2 t}$ are the relative total pressure of the inlet and outlet of the impeller, respectively, $P_{1 s}$ and $P_{2 s}$ are relative the static pressure of the inlet and outlet of guide vane, respectively, $\rho$ is the constant gas density, and $u$ is the circumferential velocity of the blade tip. These above parameters are the area-weighted averages of the circumferentially section at a specified blade height.

The larger the total pressure rise coefficient, the greater the contribution at a specific radial height to the dynamic head gained by the flow through the impeller. It can be seen from Figure 12 that the total pressure rise coefficient is relatively high in the range $R=0-0.8$, indicating that it is the main working area of the blade. The range $R=0.8-1.0$ is near the blade tip, in which the total pressure rise coefficient decreases rapidly, owing to tip leakage [30,33]. At the three blade pitch angles of $\beta=29^{\circ}, 32^{\circ}$ and $35^{\circ}$, the total pressure rise coefficient with $\theta=3.0^{\circ}$ across the entire blade height range is higher than that of the original fan with $\theta=0^{\circ}$, especially in the $\beta=35^{\circ}$ case, indicating that the forward-skewed blade can effectively improve the impeller total pressure rise, in agreement with Figure 7, and the improved effect is greater at larger blade pitch angles. The static pressure recovery coefficient of the guide vane decreases monotonically with increasing blade height, and the static pressure recovery of the vanes operating with a forward-skewed blade impeller upstream of them is higher at all three blade pitch angles. However, the gain at $\beta=29$ and $35^{\circ}$ is slightly lower than that at the design condition of $\beta=32^{\circ}$. In summary, the $\theta=3.0^{\circ}$ blade can effectively raise the stage performance of the impeller and guide vane at the three blade pitch angles.

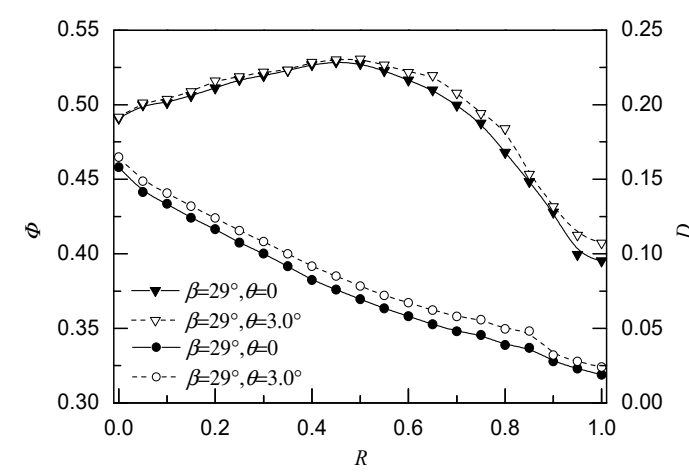

(a)

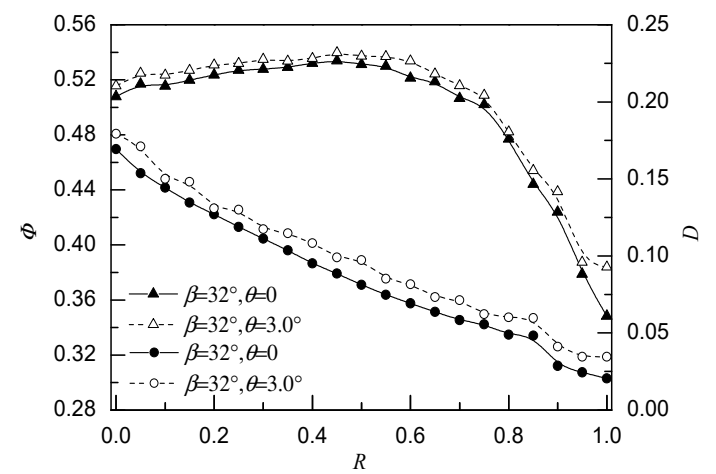

(b)

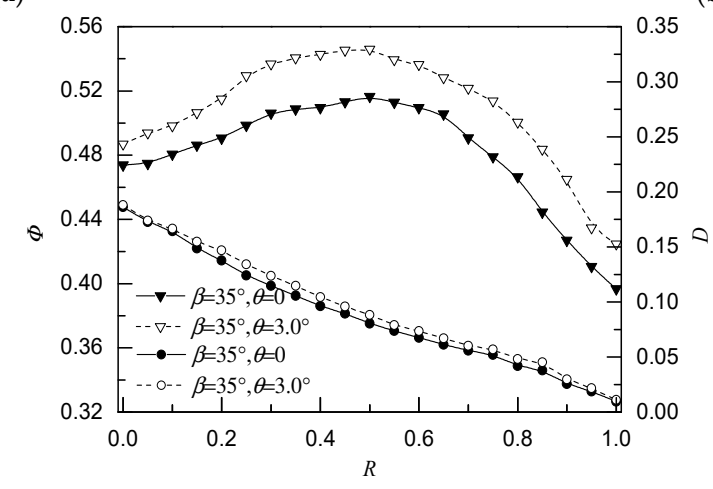

(c)

Figure 12. Distribution of total pressure rise and diffusion coefficient. (a) $\beta=29^{\circ} ;$ (b) $\beta=32^{\circ}$; (c) $\beta=35^{\circ}$.

\subsection{Distribution of Specific Entropy Production Rate}

Specific entropy production rate (SEPR) can reflect the magnitude of energy loss in a flow, that is, the aggravation of flow loss can be characterised with an increased SEPR. The total entropy production rate includes two parts induced by the viscous dissipation and turbulent dissipation in a turbulent flow [44]. To further explore the phenomenon of tip leakage, Figure 13 presents the SEPR distribution at the tip of the original blade and forward-skewed blade at $\beta=29^{\circ}, 32^{\circ}$ and $35^{\circ}$. As the 
rotation of the impeller disturbs the axial boundary layer over the casing, the SEPR near the blade is much larger than that in the flow passage, and the occurrence of the tip leakage causes the SEPR near the tip of suction/pressure side to rise, leading to the densely packed SEPR contours shown in Figure 13. However, the spacing between the SEPR contours on the pressure side is larger, indicating a comparatively lower SEPR gradient, and the SEPR on the pressure side is lower than that on the suction side under the action of leakage vortex. This difference gradually extends to the region downstream of the blade leading edge, and reduces at the impeller exit, as indicated with A. Figure 13 shows that the maximum SEPR at the tip section of the forward-skewed blades is significantly smaller than with the original blade, as indicated with B, particularly at the blade trailing edge (indicated with C), but the impact of the skewed blades on the SEPR distribution at the blade leading edge and in the flow passage between blades is not obvious. Figure 13 shows that the forward skewing design of the blade can reduce the SEPR at the blade tip and the energy loss rate, namely, by probably reducing the leakage loss and mitigating the tip leakage. This analysis also supports the conclusion of the effect of the $\theta=3.0^{\circ}$ blade on the tip leakage at the same blade pitch angles presented in Sections 3.2-3.5.

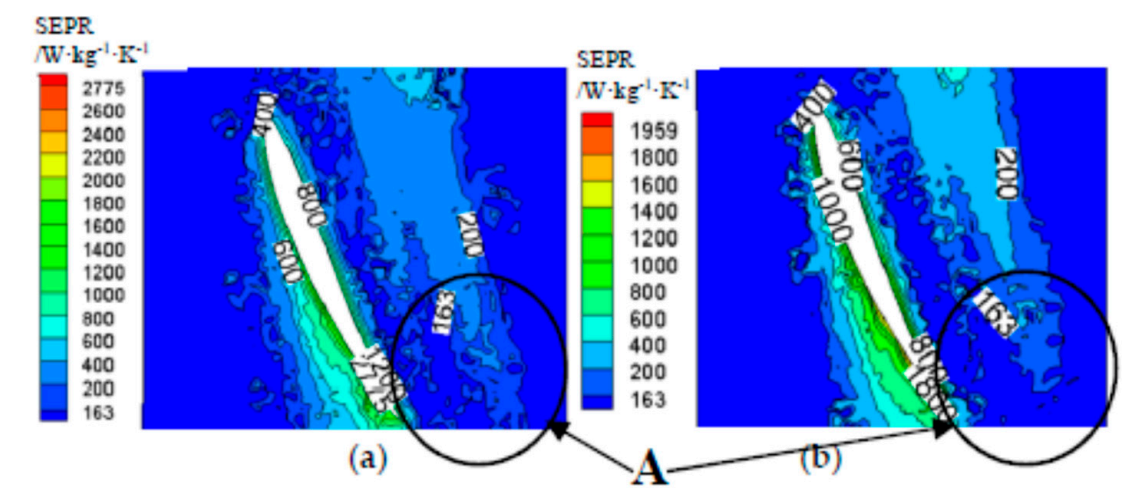

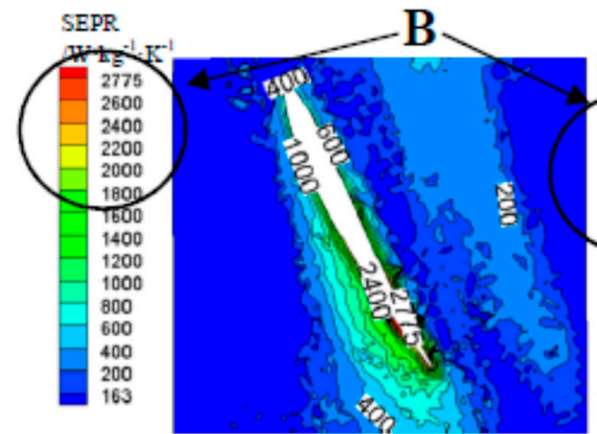

(c)

SEPR

$\mathrm{W} \cdot \mathrm{kg}^{-1} \cdot \mathrm{K}^{-1}$
2612
2600
2400
2200
2000
1800
1600
1400
1200
1000
800
600
400
200
163

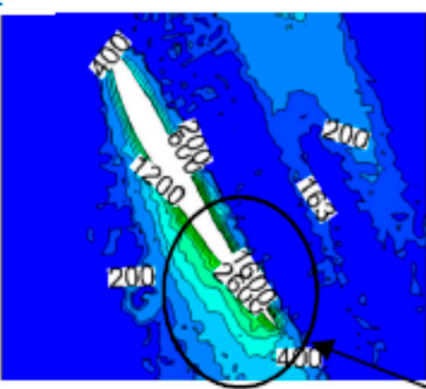

(e)

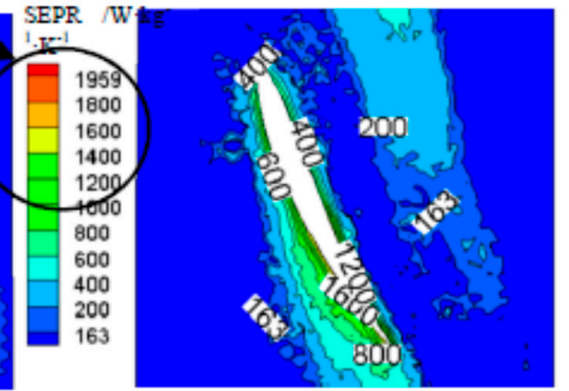

(d)

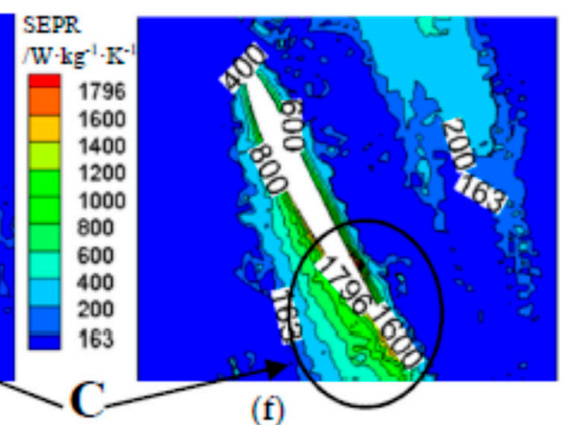

(f)

Figure 13. Specific entropy production rate (SEPR) distribution at blade tip of forward-skewed and original blades for different blade pitch angles. (a) $\beta=29^{\circ}, \theta=0^{\circ}$; (b) $\beta=29^{\circ}, \theta=3.0^{\circ}$; (c) $\beta=32^{\circ}$, $\theta=0^{\circ}$; (d) $\beta=32^{\circ}, \theta=3.0^{\circ}$; (e) $\beta=35^{\circ}, \theta=0$; (f) $\beta=35^{\circ}, \theta=3.0^{\circ}$. 


\subsection{Distribution of Specific Turbulent Kinetic Energy}

Specific turbulent kinetic energy (STKE) refers to the kinetic energy of a unit mass of fluid caused by the flow unsteadiness. The magnitude of STKE reflects the strength of the turbulence. To avoid rubbing between the rotating and static parts, a gap between the impeller blade tip and the casing is imposed. A part of the fluid flows through this tip clearance gap under the pressure difference between the blade suction/pressure sides, resulting in an undesirable leakage flow. Then the leakage flow mixes with the main flow in the flow passage, a leakage vortex is formed at the tip corner of the suction surface, which generates a turbulent flow with a strong momentum transfer rate [22]. By the presence of the tip leakage vortex, STKE is high at the blade tip, whereas it is appreciably lower in the other regions, as shown in Figure 14. The flow is prone to separating at the leading edge and to interacting with the leakage vortex, resulting in the more complicated flow and higher STKE in the upper region of the flow passage.

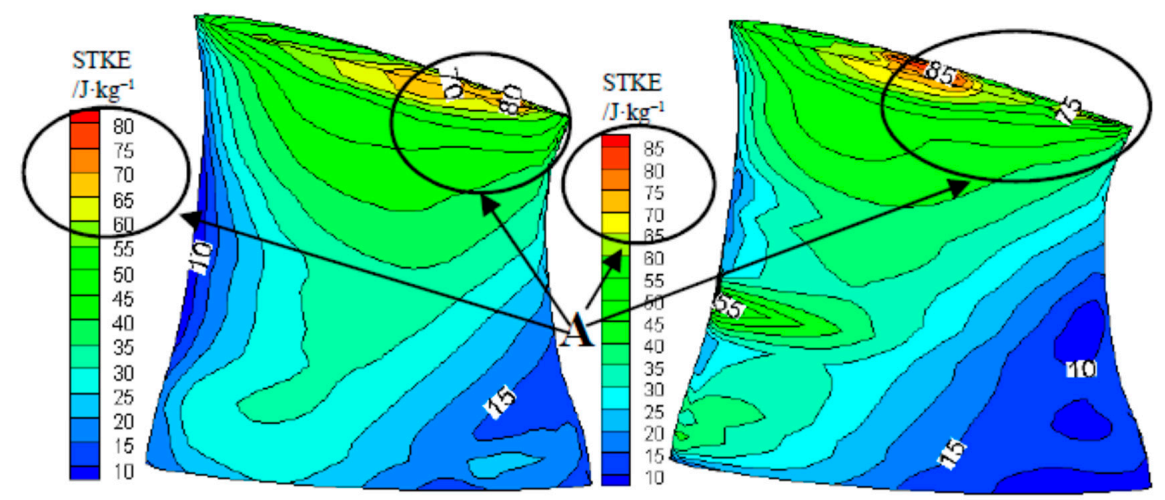

(a)

(b)

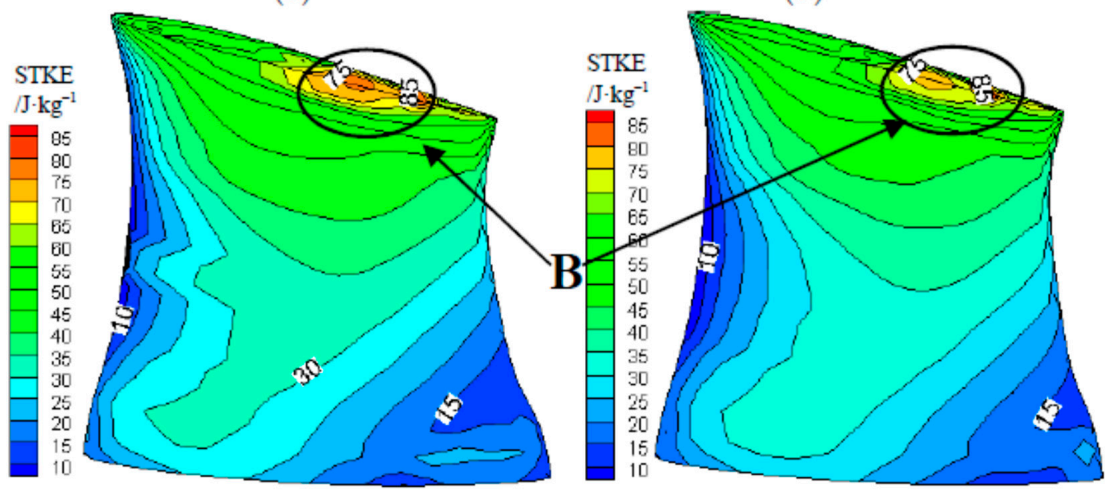

(c)

(d)

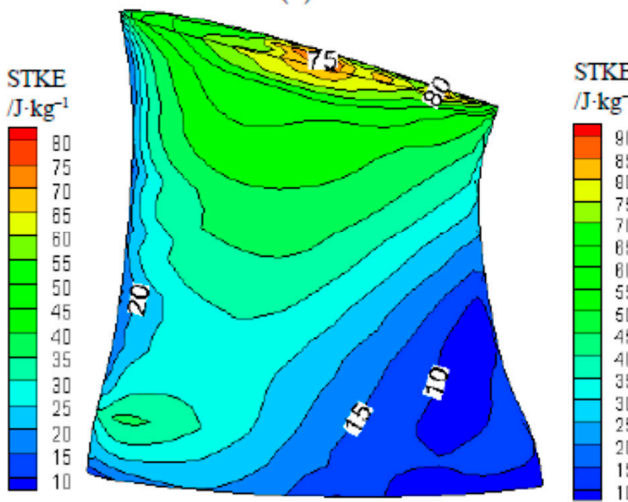

(e)

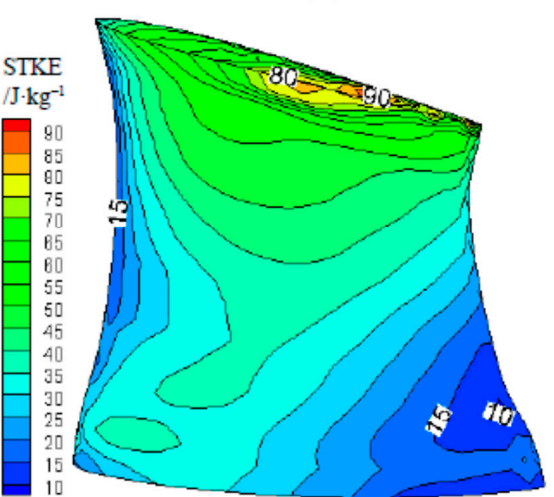

(f)

Figure 14. Specific turbulent kinetic energy (STKE) distribution on the surface of forward-skewed and original blades with different blade pitch angles. (a) $\beta=29^{\circ}, \theta=0^{\circ}$; (b) $\beta=29^{\circ}, \theta=3.0^{\circ}$; (c) $\beta=32^{\circ}$, $\theta=0^{\circ}$; (d) $\beta=32^{\circ}, \theta=3.0^{\circ}$; (e) $\beta=35^{\circ}, \theta=0 ;(\mathbf{f}) \beta=35^{\circ}, \theta=3.0^{\circ}$. 
Close inspection of Figure 14 shows that for $\beta=29^{\circ}$ and $35^{\circ}$, STKE at the tip is markedly increased after blade skewing, as indicated with $\mathrm{A}$, while for $\beta=32^{\circ}$, STKE at the tip of $\theta=3.0^{\circ}$ does not appreciably change compared to the corresponding prediction with a $\theta=0^{\circ}$ blade, but the area of the high STKE is expanded, as indicated with B, leading to an overall increase in STKE over the blade surface. That is, the blades with forward skewed of $\theta=3.0^{\circ}$ increase the turbulent kinetic energy and turbulence intensity at design and off-design conditions.

\section{Conclusions}

Forward-skewed blades can effectively improve the aerodynamic performance of a variable-pitch axial fan. The skewing angle of $\theta=3.0^{\circ}$ is a preferred choice for the design condition of $\beta=32^{\circ}$ in this study. The aerodynamic performance based on $\theta=3.0^{\circ}$ scheme shows that at blade pitch angles of $\beta=29^{\circ}, 32^{\circ}$ and $35^{\circ}$, the total pressure rise and efficiency of the fan under the highest efficiency point are predicted to change by $-0.55 \%, 2.99 \%$, and $-0.53 \%$, and $1.39 \%, 0.16 \%$, and $2.11 \%$, respectively. That is, a skewing angle of $\theta=3.0^{\circ}$ can improve the fan's performance and presents good adaptability at the reduced and increased blade pitch angles.

The forward-skewed design of blades has a greater impact on the through flow. At all three blade pitch angles tested, the axial velocity under $\theta=3.0^{\circ}$ is increased at the middle and lower parts of blades, which enhances the flow rate and delays the occurrence of the separation flow in the blade root zone, resulting in a more stable flow in the root and favourable conditions to enlarge the stall margin. The axial velocity and specific entropy production rate in the tip per are decreased, and the static pressure difference between the suction/pressure sides is reduced, leading to a reduction in the driving force for generating tip leakage. The specific entropy production rate is diminished at the blade tip, thereby the phenomenon of tip leakage is possibly mitigated, which would reduce the leakage losses and promote the fan's performance. Increasing the blade pitch angle can improve the flow field in the root induced by forward-skewed blades. The forward-skewed blade effectively improves the work output of the impeller, and this improvement increases with the blade pitch angle. Meanwhile the recovery ability of the static pressures of the guide vane is raised, but this effect at $\beta=29^{\circ}$ and $35^{\circ}$ is predicted to be slightly lower than that at the design condition of $\beta=32^{\circ}$.

Author Contributions: Conceptualization, X.Y. and C.L.; methodology, software, validation, F.F. and R.Z.; formal analysis, F.F. and X.Y.; investigation, X.Y., F.F. and R.Z.; writing-original draft preparation, X.Y. and F.F.; writing-review and editing, C.L.; supervision, X.Y. and C.L.; funding acquisition, C.L.

Funding: This research was funded by National Natural Science Foundation of China (Grant No. 11602085) and Fundamental Research Funds for the Central Universities of Ministry of Education of China (Grant No. 2015MS105).

Conflicts of Interest: The authors declare no conflict of interest.

\section{Nomenclature}

$D \quad$ static pressure recovery coefficient of diffuser, $D=2\left(P_{2 s}-P_{1 s}\right) / \rho u^{2}$

$P_{1 s} / P_{2 s} \quad$ static pressure of the inlet and outlet of guide vane, $\mathrm{Pa}$

$P_{1 t} / P_{2 t} \quad$ total pressure of the inlet and outlet of impeller, $\mathrm{Pa}$

$P_{s t} \quad$ static pressure, $\mathrm{Pa}$

$P_{t} \quad$ total pressure rise, $\mathrm{Pa}$

$Q_{v} \quad$ volume flow rate, $\mathrm{m}^{3} \cdot \mathrm{s}^{-1}$

$r \quad$ radial blade height, $\mathrm{mm}$

$r_{h} \quad$ hub radius, $\mathrm{mm}$

$r_{t} \quad$ tip radius, $\mathrm{mm}$

$R \quad$ relative blade height, $R=\left(r-r_{h}\right) /\left(r_{t}-r_{h}\right)$

SEPR specific entropy production rate, $\mathrm{W} \cdot \mathrm{kg}^{-3} \cdot \mathrm{K}^{-1}$

STKE specific turbulent kinetic energy, $\mathrm{J} \cdot \mathrm{kg}^{-1}$

$u \quad$ circumferential velocity of the blade tip, $\mathrm{m} \cdot \mathrm{s}^{-1}$

$v_{a} \quad$ axial velocity, $\mathrm{m} \cdot \mathrm{s}^{-1}$

$\beta \quad$ blade angle, ${ }^{\circ}$ 
$\eta \quad$ total-to-total efficiency, $\%$

$\theta \quad$ skewed angle, ${ }^{\circ}$

$\rho \quad$ gas density, $\mathrm{kg} \cdot \mathrm{m}^{-3}$

$\Phi \quad$ total pressure rise coefficient of impeller, $\Phi=2\left(P_{2 t}-P_{1 t}\right) / \rho u^{2}$

\section{References}

1. Li, C.; Li, X.; Li, P.; Ye, X. Numerical investigation of impeller trimming effect on performance of an axial flow fan. Energy 2014, 75, 534-548. [CrossRef]

2. Ye, X.; Li, P.; Li, C.; Ding, X. Numerical investigation of blade tip grooving effect on performance and dynamics of an axial flow fan. Energy 2015, 82, 556-569. [CrossRef]

3. He, W.; Dai, Y.; Han, D.; Yue, C.; Pu, W. Influence from the rotating speed of the windward axial fans on the performance of an air-cooled power plant. Appl. Therm. Eng. 2014, 65, 14-23. [CrossRef]

4. Li, Y.; Ouyang, H.; Du, Z. Experimental research on aerodynamic performance and exit flow field of low pressure axial flow fan with circumferential skewed blades. J. Hydrodyn. 2007, 19, 579-586. [CrossRef]

5. Vad, J.; Kwedikha, A.R.A.; Horváth, C.; Balczó, M.; Lohász, M.M.; Régert, T. Aerodynamic effects of forward blade skew in axial flow rotors of controlled vortex design. Proc. Inst. Mech. Eng. Part A J. Power Energy 2007, 221, 1011-1023. [CrossRef]

6. Jin, G.; Ouyang, H.; Wu, Y.D.; Du, Z. Experimental and numerical investigations of the tip leakage flow of axial fans with circumferential skewed blades under off-design conditions. Proc. Inst. Mech. Eng. Part C J. Mech. Eng. Sci. 2010, 224, 1203-1216. [CrossRef]

7. Jin, G.; Ouyang, H.; Du, Z. Experimental investigation of unsteady flow in axial skewed fans according to flow rates. Exp. Therm. Fluid Sci. 2013, 48, 81-96. [CrossRef]

8. Jin, Y.; Liu, D.; Wen, Z. Optimization design for skew and sweep parameters of mine contra-rotating axial fan two-stage blades. J. China Coal Soc. 2010, 10, 1754-1759.

9. Cai, N.; Li, D.; Zhong, F. Optimum design and experiment on skewed-swept rotating blades. J. Shanghai Jiaotong Univ. 1997, 31, 81-85.

10. Ouyang, H.; Li, Y.; Du, Z.-H.; Zhong, F.-Y. Experimental study on aerodynamic and aero-acoustic performance of low pressure axial flow fan with circumferential skewed blades. J. Aerosp. Power 2006, 21, 668-674.

11. Li, Y.; Ouang, H.; Du, Z. Optimized design based on skewed and swept blade technology. J. Eng. Therm. Energy Power 2007, 22, 605-611.

12. Krömer, F.; Müller, J.; Becker, S. Investigation of aeroacoustic properties of low-pressure axial fans with different blade stacking. AIAA J. 2018, 56, 1507-1518. [CrossRef]

13. Zhou, X.; Wang, S.; Wang, J. Study on aerodynamic performance of axial flow fan with bowed blade based on Bezier function. J. Huazhong Univ. Sci. Technol. Nat. Sci. Ed. 2013, 3, 106-109.

14. Zenger, F.; Herold, G.; Becker, S. Acoustic characterization of forward- and backward-skewed axial fans under increased inflow turbulence. AIAA J. 2017, 55, 1241-1250. [CrossRef]

15. Bamberger, K.; Carolus, T. Optimization of axial fans with highly swept blades with respect to losses and noise reduction. Noise Control Eng. J. 2012, 60, 716-725. [CrossRef]

16. Beiler, M.; Carolus, T. Computation and measurement of the flow in axial flow fans with skewed blades. J. Turbomach. 1999, 121, 59-66. [CrossRef]

17. Liu, Z.; Xiao, R.; Lü, T.; Li, S. Effect of swept blade on hump and cavitation characteristics of axial flow pump. J. Drainage Irrig. Mach. Eng. 2012, 3, 4.

18. Xu, W.; Du, X.; Wang, S.; Wang, Z. Correlation of solidity and curved blade in compressor cascade design. Appl. Therm. Eng. 2018, 131, 244-259. [CrossRef]

19. Starzmann, R.; Carolus, T. Effect of blade skew strategies on the operating range and aeroacoustic performance of the wells turbine. J. Turbomach. 2014, 136, 011003. [CrossRef]

20. Li, C.; Lin, Q.; Ding, X.; Ye, X. Performance, aeroacoustics and feature extraction of an axial flow fan with abnormal blade angle. Energy 2016, 103, 322-339. [CrossRef]

21. Zhang, L.; Zhang, L.; Zhang, Q.; Jiang, K.; Tie, Y.; Wang, S. Effects of the second-stage of rotor with single abnormal blade angle on rotating stall of a two-stage variable pitch axial fan. Energies 2018, 11, 3293. [CrossRef] 
22. Gou, Y.; Shi, X.; Zhou, J.; Qiu, X.; Chen, X. Characterization and effects of the shock losses in a parallel fan station in the underground mine. Energies 2017, 10, 785.

23. Ye, X.; Zhang, J.; Li, C. Effect of blade tip pattern on performance of a twin-stage variable-pitch axial fan. Energy 2017, 126, 535-563. [CrossRef]

24. Denton, J.D. The effect of lean and sweep on transonic fan performance: A computational study, Task quarterly. Propuls. Power Res. 2002, 6, 7-23.

25. Mao, X.; Liu, B.; Zhao, H. Numerical analysis of the circumferential grooves casing treatment in a counter-rotating axial flow compressor. Appl. Therm. Eng. 2018, 130, 29-39. [CrossRef]

26. Wang, Y.; Chen, W.; Wu, C.; Ren, S. Effects of tip clearance size on the performance and tip leakage vortex in dual-rows counter-rotating compressor. Proc. Inst. Mech. Eng. Part G J. Aerosp. Eng. 2015, 229, 1953-1965. [CrossRef]

27. Zhang, L.; Wang, R.; Wang, S. Simulation of broadband noise sources of an axial fan under rotating stall conditions. Adv. Mech. Eng. 2015, 6, 507079. [CrossRef]

28. Ghasemian, M.; Nejat, A. Aerodynamic noise prediction of a horizontal axis wind turbine using improved delayed detached eddy simulation and acoustic analogy. Energy Convers. Manag. 2015, 99, 210-220. [CrossRef]

29. Zhu, X.; Hu, C.; Yang, X.; Du, Z. Dynamic mode decomposition analysis of the unsteady flow in a centrifugal compressor volute. J. Aerosp. Eng. 2019, 32, 04018136. [CrossRef]

30. Han, S.; Zhong, J. Effect of blade tip winglet on the performance of a highly loaded transonic compressor rotor. Chin. J. Aeronaut. 2016, 29, 653-661. [CrossRef]

31. Jung, Y.-J.; Jeon, H.; Jung, Y.; Lee, K.-J.; Choi, M. Effects of recessed blade tips on stall margin in a transonic axial compressor. Aerosp. Sci. Technol. 2016, 54, 41-48. [CrossRef]

32. Kameier, K.; Neise, W. Experimental study of tip clearance losses and noise in axial turbomachines and their reduction. J. Turbomach. 1997, 119, 460-471. [CrossRef]

33. Moghadam, S.M.A.; Meinke, M.; Schröder, W. Analysis of tip-leakage flow in an axial fan at varying tip-gap sizes and operating conditions. Comput. Fluids 2019, 183, 107-129. [CrossRef]

34. Wu, Y.; An, G.; Wang, B. Numerical investigation into the underlying mechanism connecting the vortex breakdown to the flow unsteadiness in a transonic compressor rotor. Aerosp. Sci. Technol. 2019, 86, 106-118. [CrossRef]

35. Lin, S.-C.; Tsai, M.-L. An integrated performance analysis for a backward-inclined centrifugal fan. Comput. Fluids 2012, 56, 24-38. [CrossRef]

36. Zhou, X.; Zhao, Q.; Cui, W.; Xu, J. Investigation on axial effect of slot casing treatment in a transonic compressor. Appl. Therm. Eng. 2017, 126, 53-69. [CrossRef]

37. Cui, J.; Ye, X.; Li, C. Simulation of casing treatment effect on the performance of an axial flow fan. J. Fluid Mach. 2016, 44, 11-17.

38. Ghasemian, M.; Nejat, A. Aero-acoustics prediction of a vertical axis wind turbine using Large Eddy Simulation and acoustic analogy. Energy 2015, 88, 711-717. [CrossRef]

39. ОлоуМаһuо ребенком, Т.C. Ventilator Pneumatic Schematic and Performance Curve; China Coal Ind. Press: Beijing, China, 1986; pp. 336-346.

40. Ouyang, H. Study on a New Type Reversible Axial Flow Fan with Skewed and Combined Blades. Ph.D. Thesis, Shanghai Jiaotong University, Shanghai, China, 2003.

41. Luan, H.; Weng, L.; Luan, Y.; Zhang, Y.; Chen, P. Numerical study on aerodynamic noise performances of axial spacing in a contra-rotating axial fan. J. Vibroeng. 2016, 18, 5605-5618.

42. Galindo, J.; Tiseira, A.; Navarro, R.; López, M.A. Influence of tip clearance on flow behavior and noise generation of centrifugal compressors in near-surge conditions. Int. J. Heat Fluid Flow 2015, 52, 129-139. [CrossRef]

43. Jung, J.H.; Joo, W.-G. Effect of tip clearance, winglets, and shroud height on the tip leakage in axial flow fans. Int. J. Refrig. 2018, 93, 195-204. [CrossRef]

44. Herwig, H.; Kock, F. Direct and indirect methods of calculating entropy generation rates in turbulent convective heat transfer problems. Heat Mass Transf. 2007, 43, 207-215. [CrossRef]

(C) 2019 by the authors. Licensee MDPI, Basel, Switzerland. This article is an open access article distributed under the terms and conditions of the Creative Commons Attribution (CC BY) license (http://creativecommons.org/licenses/by/4.0/). 